\title{
Teorizar, repetir e patologizar: a leitura psicanalítica sobre as homossexualidades e transexualidades*1
}

\section{Theorizing, repeating and pathologizing: the psychoanalytical understanding of homosexualities and transsexualities}

\author{
Pedro Teixeira de Almeida*2 \\ Matheus Ferreira de Castro*3 \\ Sarug Dagir Ribeiro*4
}

O objetivo deste trabalho é localizar o entrecruzamento dos elementos comuns ou que se repetem nas teorizações psicanaliticas em torno da homossexualidade e da transexualidade. Passando pela caracterização dos discursos psicanalíticos desde Freud e Lacan até nossos dias, constatamos uma espécie de repetição nessas teorizações, uma vez que a homossexualidade foi historicamente atrelada a uma escolha de objeto narcísica e à perversão, fato que se repete na contemporaneidade em postulações sobre as transexualidades, tidas como psicose e perversão. Conclui-se que muitos textos psicanalíticos se articulam, se entrelaçam e se suplementam numa repetição de teorizações como a tese do hermafroditismo psíquico que serve de base etiológica tanto para as homossexualidades como para as transexualidades.

Palavras-chave: Homossexualidade, psicanálise, repetição, transexualidade

*1 O presente artigo é fruto de um trabalho de pesquisa realizado ao longo de um ano, sob orientação de Sarug Dagir Ribeiro no curso da disciplina Psicanálise e Transexualidades.

*2,3,4 Universidade Federal de Minas Gerais - UFMG (Belo Horizonte, MG, Brasil). 


\section{Introdução}

Esta pesquisa surge a partir de alguns questionamentos sobre o tratamento dispensado pela psicanálise às expressões da sexualidade que desviam da norma heterossexual, mais especificamente as homossexualidades e as transexualidades. Apresentamos um breve panorama sobre as principais produções em psicanálise a respeito dessa temática, fato que nos introduz num jogo teórico-clínico de reiteração de posturas etiológicas comuns às homossexualidades e transexualidades. ${ }^{1}$ A utilização do significante etiologia não se dá ao acaso: a palavra, que também remete ao campo médico responsável pelo estudo das causas das doenças, funciona como um articulador para pensar a linearidade dos modos com os quais a psicanálise tem lidado com as experiências não heterossexuais, sob o auspício das hipóteses sobre falhas narcísicas, pelas sombras de uma mãe psicotizante ou, mesmo, a partir de uma confusão do falo simbólico e literalização castrativa no real do corpo (Lattanzio \& Ribeiro, 2017). Desse modo, apreende-se as sexualidades homossexual e transexual pela via do negativo, da falha e da falta. Questionamo-nos então: por que a psicanálise insiste em produzir etiologias para as homossexualidades e para as transexualidades?

Para responder a essa pergunta, estruturamos este trabalho da seguinte forma: na primeira seção realizamos uma incursão histórica em torno da invenção do Dispositivo de Sexualidade e a essencialização da noção de sexo biológico por meio do dimorfismo sexual presente desde o século XVIII na sociedade ocidental (Foucault, 2014), ideias que influenciaram a psicanálise desde seu nascedouro. $\mathrm{Na}$ segunda seção, analisamos criticamente a patologização das

${ }^{1}$ Cabe ressaltar que atualmente nem todas as posturas teórico-clínicas de abordagem psicanalítica patologizam as homossexualidades e as transexualidades; dentre essas posturas estão: Bedê e Belo (2019), Ceccarelli e Andrade (2018), Ceccarelli (2017), Ceccarelli (2013a), França e Mazzini (2018), dentre outras. 


\section{ARTIGOS}

homossexualidades desde o freudismo às concepções pós-freudianas (Costa, 1995). Na terceira seção, pautamos uma análise crítica da patologização das transexualidades (Arán, 2006). Na quarta demonstramos as consequências políticas e clínicas desse tipo de teorização (Ayouch \& Charafeddine, 2013; França \& Mazzini, 2018). Por fim, apoiando-nos na ideia de que "a teoricogênese reproduz a ontogênese" (Laplanche, 1992, p. 17), argumentamos que a própria teorização psicanalítica estaria sujeita aos processos defensivos que ela descobre, sobretudo, nos desditos etiológicos sobre a homossexualidade e a transexualidade (Ayouch, 2015).

\section{A invenção e história das sexualidades ocidentais}

Coube aos estudos arqueológicos e genealógicos de Foucault (2017; 2014) a historicização das sexualidades ocidentais. A arqueologia foucaultiana vai nos introduzir a uma espécie de torção epistemológica experimentada pelo Ocidente a partir do século XVIII, na qual o sujeito da religião é tornado objeto das ciências, a qual the encerra verdades e essencializa sua natureza. Ao longo dessa passagem religião-ciência, vê-se tomar forma uma intensa explosão discursiva sobre o sexo, imiscuída em um cuidado sacro de não se falar diretamente sobre a sexualidade. No entanto, é sobre o sexo que se falou desde que a pastoral cristã, como explicita Foucault (2014), o introduz no discurso através da incitação de um dizer de si. A técnica da confissão cristã figura como um primeiro instrumento de colocação do sexo no discurso, técnica de extração da verdade.

Ao longo dos séculos XVIII e XIX, vê-se tomar forma no ocidente uma verdadeira scientia sexualis, preocupada não apenas em desvelar o sexo, mas catalogá-lo, introduzindo suas sensações e prazeres em um regime de vida e morte, saúde e doença. O sexo se torna réu de toda uma aparelhagem do poder que constitui saberes sobre a essência do sujeito: "nós dizemos a sua verdade, decifrando o que dela ele nos diz; e ele nos diz a nossa, liberando o que estava oculto" (Foucault, 2014, pp. 78-79). É importante destacar que a proposta foucaultiana pensa o poder para além de uma instância puramente jurídica e repressiva. O poder é descrito como um campo de forças que supera sua noção verticalizada ou horizontalizada. Esse poder microfísico, pulverizado, se imiscuiria nas relações mais cotidianas nas quais os indivíduos se engajam (Foucault, 2017). Ele não apenas reprime, mas atrai e produz, concatenando um circuito de prazeres e saberes ao mesmo tempo como objeto do poder e força reificadora do mesmo. 
Foucault (2014) chamou de Dispositivo da Sexualidade a todo esse conjunto de técnicas polimorfas do poder e de aparelhagem que introduz saberes sobre o sexo. Aqui a intenção não apenas gira em torno da manutenção do corpo social, como acontece pela função interditora e matrimonial do Dispositivo da Aliança, mas, produzir, inventar e penetrar nesse mesmo corpo, rearticulando formas de sujeição e controle (Foucault, 2006). Através desse objeto quase infinito, inesgotável, que é a sexualidade, o poder se introduz nas relações mais íntimas e secretas do sujeito com o outro e do sujeito consigo mesmo. Nas palavras do autor "há dois significados para a palavra sujeito: sujeito a alguém pelo controle e dependência, e preso à sua própria identidade por uma consciência e autoconhecimento. Ambos sugerem uma forma de poder que subjuga e torna sujeito a" (Foucault, 1995, p. 235). Assim, existem três tipos de lutas: contra as formas de dominação (étnica, social e religiosa); contra as formas de exploração que separam os indivíduos daquilo que eles produzem e contra aquilo que liga o indivíduo a si mesmo; contra a submissão da subjetividade. Nesse sentido, a sexualidade funciona como um ponto de apoio sempre revolto, fluido, para que o poder avance, por entre linhas intercruzadas em ramificações infinitas. Esse sistema elencou o sexo como balizador da saúde e da doença, marcador apropriado pela burguesia do século XVIII que encontra na sexualidade heterossexual seu diferencial de classe.

As grandes narrativas sobre a sexualidade operam a marcação de uma pretensa verdade no real do corpo. As práticas sexuais anormais passam a ser nomeadas e classificadas em um regime de saúde-doença comparada com aquela eleita como sexualidade normal e saudável (a heterossexualidade). Apenas a partir da delimitação do campo do abjeto, da monstruosidade, no qual habitariam o homossexual e o onanista, é que se institui a norma heterossexual (Foucault, 2001). Nesse sentido, há uma multiplicação das perversões e uma incitação da heterogeneidade sexual, acompanhado pelo jogo de poderes (religiosos, médicos, psiquiátricos) que passaram a regular a linha entre o lícito e o ilícito, o normal e o patológico. As técnicas de confissão produziram narrativas que possibilitaram a localização das verdades desviantes dos anormais, utilizadas na composição da figura emblemática do monstro sexual. É nesse sentido que o discurso médico-psiquiátrico instrumentaliza a noção comumente utilizada de sexo essencializado no corpo pelos atributos masculinos e femininos, naturalizando uma suposta complementaridade genital na heterossexualidade (Katz, 1996).

Desse modo, as sexualidades homossexual e heterossexual são fortemente constituídas no entorno do dimorfismo sexual (Costa, 1995). Torna-se 


\section{ARTIGOS}

vigente a organização dos corpos a partir de caracteres anatomofisiológicos essencializados como verdades eternas do masculino e do feminino. Essa proposta ocupará um lugar privilegiado na construção identitária do homo sexualis moderno, influenciando fortemente as teorias psicológicas, dentre as quais a teorização psicanalítica freudiana e pós-freudiana, herdeiras de sua influência. Assim, Foucault (2014) inscreve a psicanálise no quadro geral do Dispositivo da Sexualidade:

Mas eis que a psicanálise, que parecia, em suas modalidades técnicas, colocar a confissão da sexualidade fora da soberania familiar, reencontrava, no próprio seio dessa sexualidade, como princípio de sua formação e chave de sua inteligibilidade, a lei da aliança, os jogos mesclados dos esponsais e do parentesco, o incesto. A garantia de que lá, no fundo da sexualidade de cada um, ia se encontrar a relação pais-filhos permitia, no momento em que tudo parecia indicar o processo inverso, manter a fixação do dispositivo de sexualidade sobre o sistema da aliança. (p. 123)

Ao longo da história da psicanálise, assistimos inúmeras tentativas de encontrar uma etiologia para os indivíduos que não se desenvolveram pela norma heterossexual cis-gênero. No escopo deste artigo, seguiremos pelas leituras psicanalíticas sobre a homossexualidade e a transexualidade em Freud e nos pós-freudianos.

\section{As homossexualidades vistas pela psicanálise}

No primeiro dos três ensaios Freud (1905/2016a) retoma a noção de inversão sexual, cunhada em 1897 por Havelock Ellis, para dizer dos desvios do instinto, tanto em relação ao seu objeto quanto em relação à sua meta. $\mathrm{O}$ autor retoma algumas explicações correntes sobre a inversão sexual, dando destaque à figura do invertido sexual no campo da degeneração, formulado pelo psiquiatra francês Valentin Magnan. Freud também desloca o foco de análise das características anátomo-fisiológicas ao reconhecer a independência entre o hermafroditismo somático e a inversão. A ênfase, aqui, recai sobre a não fixidez ao objeto da pulsão, afinal, segundo Freud (1905/2016a),

Para a psicanálise, isto sim, a escolha objetal independente do sexo do objeto, a possibilidade de dispor livremente de objetos masculinos e femininos, tal como se observa na infância, em estados primitivos e épocas antigas, parece ser a atitude original, a partir da qual se desenvolvem, mediante restrição por um lado ou por outro, tanto o tipo normal como o invertido. [...] Nos 
tipos invertidos, sempre se constata o predomínio de constituições arcaicas e mecanismos psíquicos primitivos. A vigência da escolha narcísica de objeto e a manutenção do significado erótico da zona anal aparecem como suas características essenciais. (pp. 34-35)

Se, por um lado, a escolha objetal é desvinculada de todo artífice naturalizante, por outro, no homossexual, caricaturado pelo invertido, estão presentes mecanismos psíquicos primitivos e constituições arcaicas. Essa visão reservará ao homossexual um lugar patologizante e inferior, inclusive evolutivamente.

Em outro texto Freud (1910/2015) explica a etiologia da homossexualidade na fixação à figura da mãe. $\mathrm{O}$ autor se refere à homossexualidade como produto de um vínculo intenso com a mãe durante os primórdios da organização psíquica, acompanhado pelo carinho excessivo por parte desta última. "É como se a presença do pai assegurasse ao filho a correta decisão acerca da escolha de objeto, para o sexo oposto" (pp. 115-116). Ao se identificar com a mãe, o menino recalcacaria seu amor por ela, partindo em uma busca, autoerótica por excelência, por outros parceiros a quem pudesse amar como uma vez sua mãe o amou. Freud (1910/2015) menciona 82 a teoria sexual infantil da universalidade do pênis, ou seja, a crença de que a mãe possui um pênis, que também explicaria a escolha de objeto homossexual. O menino após descobrir que a mulher não possui um pênis, seria tomado pelo horror ao genital feminino, em um dos possíveis motivos para a "homossexualidade permanente" (p. 112). Essa teoria sexual infantil pode abrigar uma fixação posterior a esse objeto desejado, o pênis da mulher, fixação que "deixa rastros inapagáveis na vida psíquica do menino, na qual cada parte da pesquisa sexual infantil passou por um aprofundamento" (p. 95). Essa recusa diz respeito, precisamente, à recusa da diferença, aqui sexual, na qual seria rechaçada a percepção da realidade e da alteridade.

Por fim, temos o texto "Sobre a psicogênese de um caso de homossexualidade feminina", publicado no ano de 1920, no qual Freud (1920/2011) após uma descrição detalhada das equações e dinâmicas libidinais da vida de uma jovem que alinhava-se à eleição de objeto homossexual ressalva que: "não cabe à psicanálise resolver o problema da homossexualidade. Ela tem de contentar-se em desvendar os mecanismos psíquicos que levaram à decisão na escolha de objeto, e em seguir os caminhos que vão deles às disposições instintuais" (p. 130). A homossexualidade é colocada no mesmo patamar da heterossexualidade, ambas como soluções e desenlaces possíveis à problemática edipiana. 


\section{ARTIGOS}

A sobredeterminação das análises dos casos de homossexualidade ao longo da obra freudiana aponta para uma multiplicidade de leituras sobre a temática (Costa, 1995). Mesmo que essa multiplicidade ateste que as sexualidades não heterossexuais são tão legítimas quanto essa última, vemos que as teorizações pós-freudianas (Lattanzio \& Ribeiro, 2017) andaram pelo caminho contrário, muitas vezes engajadas na busca pelas causas etiológicas, como se se tratasse de uma patologia, sufocando a diversidade do sexual infantil perverso-polimorfo. Para além disso, operando uma fixidez do objeto tributária de um aparato moralizante, como se houvesse um tipo de escolha objetal mais legítimo, saudável e normal para o campo da sexualidade.

A ideia freudiana de um vínculo extraordinário com a mãe (Freud, 1910/2015) deixa suas marcas nas produções psicanalíticas que o sucedem como, por exemplo, na proposta stolleriana sobre a constituição da masculinidade. Em contraposição a Freud, Stoller (1966) nos remete a uma primazia da feminilidade a partir do imprinting materno na criança. Nesses primeiros momentos da vida, estaríamos lançados em um jogo identificatório precoce com a mãe. Nesse sentido, construir-se menino torna-se um processo mais complexo, afinal, seria necessário não apenas seguir o livre curso de sua identidade de gênero, mas desidentificar-se da mãe primeiro, para só depois erigir a identidade masculina (Lattanzio \& Ribeiro, 2018). Processo que se vê em constante ameaça, pois haveria um núcleo identitário, constituído na relação de imprinting com a mãe, que sempre pulsaria por um retorno ao feminino.

Como dito anteriormente, a figura do homossexual foi sendo associada ao psiquismo primitivo e a recusa à diferença sexual, fato que a aproxima do campo das perversões. Levadas ao extremo, essas propostas acabam formalizando um uso normalizador da psicanálise, reiterando condutas ortopédicas e conservadoras do dispositivo analítico (Bedê \& Belo, 2019). É o que acontece, por exemplo, em algumas leituras lacanianas que denunciam a não inscrição da função paterna como ponto de barra nesses indivíduos (Lattanzio \& Ribeiro, 2017), os quais, por sua vez, extrapolam a ordem social calcada nos pressupostos de filiação e aliança.

\section{As transexualidades e a psicanálise}

O sentimento de não pertença ao gênero designado ao nascer, que geralmente é atribuído pelos pais com base no sexo anatômico é o que 
caracteriza a transexualidade e também é observável em diversas culturas ao longo da história (Millot, 1991). O chamado fenômeno transexual foi batizado por Henry Benjamin em 1966. ${ }^{2}$ A definição de Benjamin, que se inspira nas proposições de Freud e Kraft-Ebing sobre a bissexualidade, consiste em propor uma fragmentação do sexo em diversos componentes, cada um macho ou fêmea, genéticos, anatômicos, sociais, legais, psicológicos, com base nos quais o indivíduo se definiria enquanto homem ou mulher a partir do peso quantitativo de cada um desses componentes masculinos ou femininos. No caso da transexualidade, ${ }^{3}$ haveria uma discordância extrema entre os componentes biológicos e psicológicos, "o transexual representa o ponto máximo de discordância entre os sexos macho e fêmea, e mais particularmente entre seus componentes psicossociais e biomorfológicos" (Perelson, 2011, p. 3). A única terapêutica possível seria, então, o procedimento cirúrgico aliado ao tratamento hormonal, o que tornaria possível uma maior concordância entre os componentes macho-fêmea (Benjamin, 1966).

Discordamos, no entanto, do argumento utilizado por Millot (1991) e Perelson (2011), de que a oferta criaria a demanda. O argumento é construído entendendo que o fenômeno seria isolado enquanto tal, justamente no momento em que os avanços técnico-científicos permitem a realização de intervenções por meio de procedimentos cirúrgicos e a hormônio-terapia. Ora, parece-nos que a proposição de uma etiologia estará sempre atrelada à proposta de uma terapêutica como nos demonstra (Trillat, 1991). Logo, não é propriamente a oferta de cirurgia que seria responsável pelo fenômeno transexual, a menos que aceitemos a ontologização dos sexos naturalizados pela biologia na proposta dimorfista, que visa colocá-lo fora do discurso, o que, como argumentamos, parece-nos impossível (Foucault, 1995; 2014). Nossa posição vai em direção a uma primazia do discurso sobre o real do corpo, entendendo que esse real biológico supostamente fora do discurso é produzido discursivamente (Butler, 1993). Como exemplo, poderíamos

${ }^{2}$ Ainda que tenha sido Henry Benjamin o responsável por isolar o fenômeno transexual, o primeiro a utilizar o termo transexual é Magnus Hirchfeld em 1910 (Castel, 2001), visando despatologizar as homossexualidades o autor busca separar as práticas de transvestismos, enquanto não sendo específicas das homossexualidades.

${ }^{3}$ Optamos por manter o termo transexualidade mesmo nas descrições históricas que se utilizem do termo transexualismo, por irmos justamente contra a proposta de uma patologização presente no sufixo -ismo. 


\section{ARTIGOS}

citar o movimento transgender da década de 1970, que não objetivava uma assimilação do outro sexo por meio da intervenção cirúrgica, mas a refutação ativa dos estereótipos sexuais. Inclusive no campo jurídico, passa-se de uma militância que visa a acessibilidade do procedimento de redesignação sexual para uma que visa a conquista de direitos civis e um combate às discriminações policiais e econômicas (Castel, 2001; Porchat, 2014).

Parece-nos que é o retorno a Freud de Lacan, que instituirá o Édipo e a castração como condições de subjetivação e de acesso à cultura. A equação primeiro a mãe alienante e depois o pai separador que permite o indivíduo o ingresso ao simbólico, mesmo que à custa da "libra de carne" (Lacan, 1962-63/2005, p. 242). É elevada ao estatuto de estrutura com a metáfora paterna. Estrutura a-histórica e universal que acaba esquecendo os elementos envolvidos no seu processo de forjamento, bem como a própria forja em que foi concebida. Alguns psicanalistas lacanianos, no entanto, têm demonstrado a fragilidade na ideia de se supor um Édipo universal (Dunker, 2015).

A referência constante ao reconhecimento da diferença anatômica dos sexos como marco da instituição da castração vai acabar por gerar a patologização das transexualidades e homossexualidades. Millot (1991) vai conceber o sintoma transexual de se identificar como pertencente ao outro sexo como uma suplência ao significante do Nome-do-pai:

O sintoma transexual funcionaria como suplência do Nome-do-Pai na medida em que o transexual visa encarnar A mulher. Não uma mulher, do lado do "não-toda", o que resulta que nenhuma mulher é Toda, inteiramente mulher, que nenhuma vale por todas as mulheres - com efeito, a posição do transexual consiste em se querer Toda, inteiramente mulher, mais mulher que todas as mulheres e valendo por todas. [...] A mulher com M maiúsculo, precisamente aquela que Lacan diz não existir. ( p. 37)

Uma função análoga àquela concebida por Lacan (1962-63/2005) à escritura para Joyce, como um quarto elemento que vem enlaçar os registros RSI, na ausência do Nome-do-Pai. Esse seria o motivo também da ausência de sintomas psicóticos em transexuais. No entanto, diferentemente de Joyce, cuja escrita vai se inserir enquanto um sinthome que enlaça os três diferentes registros, no caso da transexualidade essa suplência se daria somente entre simbólico e imaginário; a reclamação pela cirurgia seria, então, uma tentativa de corrigir o real do sexo aos nós I e S (Millot, 1991). Posição semelhante à de Calligaris (1989) que vai enxergar na cirurgia uma tentativa de constituição, no real do corpo, de uma metáfora delirante. A operação transexual, bem como os processos de hormonização, para esses autores, viriam como 
um substituto da metáfora paterna neurótica, com a diferença de que na neurose isso se daria pelo registro simbólico enquanto na transexualidade necessitaria de uma intervenção cirúrgica. No entanto, pesquisas atuais têm problematizado a associação entre transexualidade e psicose (Ceccarelli, 2017; 2013a; Lattanzio \& Ribeiro, 2017), no sentido de enfatizar que essas formulações etiológicas não estão isentas de consequências políticas e clínicas.

\section{Consequências desse tipo de teorização}

Começaremos tratando das implicações que essa proposição de uma etiologia vai gerar na própria instituição psicanalítica. Ernest Jones era contrário em relação à possibilidade de acesso à formação psicanalítica por analistas homossexuais na IPA, com intenções de limpar a instituição de membros que pudessem ser atacados por sua sexualidade (Ayouch \& Charafeddine, 2013). Esse posicionamento acaba instaurando uma regra não dita que se perdura ao longo da história das instituições psicanalíticas. Nos Estados Unidos, por exemplo, país que teve o desenvolvimento da psicanálise muito atrelado à medicina, a despatologização da homossexualidade vai ser uma reivindicação que parte sobretudo dos movimentos de liberação gays e lésbicos. Somente em 1972 Robert Spitzer, pressionado pelas reivindicações desses movimentos, e pelas declarações de John Fryer que aponta, com o pseudônimo de dr. H., as dificuldades de ingresso em instituições psicanalíticas por conta de sua homossexualidade, dá início ao processo de retirada da categoria nosológica do DSM (Ayouch \& Charafeddine, 2013). Isso não veio sem resistência por parte dos psicanalistas, com argumentos que alegavam que a homossexualidade, com a negação da diferença sexual, culminaria em uma negação da diferença geracional, e portanto no comportamento pedófilo. Além disso, afirmavam que a militância seria mera recusa dos conflitos pessoais dos homossexuais. Um posicionamento oficial da IPA (Associação Internacional de Psicanálise) contra uma discriminação baseada na orientação sexual vai se dar somente em 1999 (Ayouch \& Charafeddine, 2013). Para além de como as próprias instituições psicanalíticas lidaram com o ingresso de analistas abertamente homossexuais em suas formações, o estrago é ainda maior quando essas são convocadas pela mídia a se pronunciarem sobre políticas públicas que envolvem a sexualidade. Apoiando-se em uma noção transindividual e a-histórica de simbólico, 


\section{ARTIGOS}

que tomam alguns significantes como função paterna, função materna na qualidade de coisa, e sempre esbarram em um entendimento literal da noção de diferença sexual. Desse modo, alguns psicanalistas vêm a público defender posições homofóbicas travestidas de opiniões científicas. Tomaremos como exemplo dois casos famosos relativamente recentes: o primeiro envolvendo a PACs $^{4}$ de 1999 e o segundo debate de 2013 sobre casamento igualitário e adoção homoparental.

No caso de 1999, a psicanálise foi convocada para discutir o casamento homossexual, por meio de noções como parentalidade, diferença sexual e filiação. Tendo uma posição contrária à união entre homossexuais, tais psicanalistas baseavam-se no argumento de que essa liberação "provocaria o apagamento da tríade heterossexualidade-casamento-filiação, implicando o esfacelamento da diferença sexual no simbólico e a consequente destruição daquilo que assegura a sociabilidade" (França \& Mazzini, 2018, p. 223). É como se, ao permitir a união homossexual, a sociedade perdesse seu sistema de classificação baseado na diferença dos sexos, cuja tríade exclui a homossexualidade. Já no caso de 2013 a substituição dos termos pai e mãe por pais no código civil é considerada uma recusa à lei da diferença dos sexos, e, portanto, como perverso. Assim, crianças criadas por casais homoparentais teriam sua estrutura simbólica danificada, por derrubar os fundamentos da filiação e aliança (Ayouch, 2015). É nesse sentido que falamos que há um tratamento dos significantes como coisa, pai e mãe, homem e mulher, instantaneamente ontologizados. Cola-se os significantes utilizados na teoria a significados muito rígidos oriundos do senso comum. Para esses autores a tríade edípica, pai-mãe-filho, implica não funções que um cuidador desempenha e que foram atreladas a esses significantes apenas historicamente, mas como homem-mulher-filho. É ainda mais assombroso elevar isso à categoria de estrutura simbólica universal e a-histórica. ${ }^{5}$ Se em 2013 e 1999 temos psicanalistas se opondo à conquista de direitos civis por parte de casais homoparentais, na questão da transexualidade isso se complica. Mesmo em relatos clínicos recentes, são evocadas as teorizações patologizantes com respeito às transexualidades. É o caso de Miranda (2015) que nos relata o caso de um homem trans que busca atendimento psicanalítico para obter

${ }^{4}$ Parceria contratual entre duas pessoas de qualquer sexo e maiores de idade. Semelhante a união estável brasileira, que foi votada em 1999.

${ }^{5}$ Dunker (2015) já se posicionou criticamente a esse respeito. 
o laudo que permitiria a cirurgia de retirada da mama. Após três entrevistas esse homem trans decide por não retornar. Em sua teorização sobre o caso ela desconfia se tratar de uma psicose, utilizando como argumento a teoria de Millot (1991) que retomamos acima. Nas palavras da autora:

A certeza de Rafaela que era um homem, me fez de início pensar que se pudesse tratar de um sujeito psicótico. A psicose é uma estrutura que comparece com frequência nos transexuais, onde se observa o empuxo à mulher preconizado por Lacan. Segundo alguns autores, entre eles Catherine Millot, na estrutura psicótica a transexualidade pode funcionar como suplência à foraclusão do significante Nome-do-Pai, mantendo a estabilidade do sujeito. (Miranda, 2015, p. 91)

Nesse relato notamos algumas características curiosas, dentre elas: a certeza de que era um homem só é tomada como indício de psicose quando se trata de um homem transgênero; no caso do homem cisgênero heterossexual que também possui essa certeza, não são levantados quaisquer tipos de suspeitas. Nesse sentido, sexo e gênero estão implicitamente colados. Ademais Millot (1991) evoca a ideia de empuxo à mulher preconizada por Lacan (1996), como uma característica observada nos transexuais. Vale perguntar qual é o transexual sobre o qual ela se refere, uma vez que se trata do caso de um homem trans. E, por último, a referência a Millot (1991) em que a transexualidade viria fazer a função de suplência do Nome-do-Pai, uma espécie de diagnóstico a priori e sem escuta, realizado em apenas três sessões.

Em águas kleinianas nos deparamos com um problema semelhante: a literalização do Édipo a partir de uma leitura que ontologiza a tríade pai-mãe-filho. Yoshida et al. (2001) nos relatam um caso clínico de uma adolescente transexual que busca o atendimento do ambulatório para a cirurgia de redesignação sexual. Além da triagem e de alguns testes, são feitas nove sessões. As autoras retomam o desenvolvimento psicosexual a partir do conceito de identificação desenvolvido pela psicanálise freudiana. Elas apontam uma ausência do pai como impossibilidade de se passar pelo Édipo normal e caminhar rumo ao desenvolvimento da masculinidade, restando, portanto, uma identificação maciça com a mãe. Nas palavras das autoras:

A falha no processo de identificação faz com que o transexual busque o reconhecimento da sua posição civil, trocando seu nome, tornando-se simbolicamente o seu próprio pai e exercendo a função paterna daquele que nomeia. Podemos pensar na exclusão da figura paterna, uma forma de negação extremada que funciona como uma dinâmica psicótica. Diferentemente do perverso, o transexual está convencido, como que num delírio, que pertence 


\section{ARTIGOS}

ao outro sexo, e vive na realidade um árduo trabalho na busca dessa transformação. (p. 97)

Dessa vez a ausência do pai real é apontada como aquilo que vai gerar a maciça identificação com a mãe restando, portanto, o caminho da psicose. O Édipo é entendido como a presença do pai e mãe reais, e os trâmites identificatórios que essas presenças implicam. Curiosamente, no caso apontado, temos uma configuração familiar que não rima com aquela prescrita pela teoria, a de uma avó que cuidará dessa criança. Parece-nos que esse tipo de diagnóstico apriorístico presente nos dois artigos citados incorre no mesmo destino de Simão Bacamarte, médico do conto de Machado de Assis $O$ alienista (1882/2019), no qual o personagem interna uma cidade inteira para perceber, sabiamente depois, que como era o único que não apresentava patologias, só ele deveria ser internado.

\section{Para além da diferença sexual}

Como vimos anteriormente, ao longo dos séculos XVIII e XIX a sexualidade foi constantemente reiterada e encerrada no corpo, macho e fêmea, na chamada teoria do two-sex-model (Costa, 1995). Assim, as homossexualidades e as transexualidades passaram a ser pensadas a partir do dispositivo de dimorfismo sexual. Essa proposta ocupa lugar central na construção identitária do sujeito moderno (Foucault, 2006), influenciando em grande medida as teorias psicológicas sobre a relação do sujeito com sua sexualidade, dentre as quais a teorização psicanalítica freudiana e pós-freudiana. Ocorre que, como todo campo do saber, a psicanálise e os psicanalistas não estão imunes ao jogo de saber-poder típico de uma época, e que engendra narrativas ideologicamente comprometidas sobre a sexualidade. Para a psicanálise, a diferenciação anatômica e seu reconhecimento, ou recusa, é pedra angular da estruturação psíquica do indivíduo (Lacan, 1955-56/1988; 1966/1998). A proposta da existência de certo hermafroditismo psíquico, por sua vez, bem como a ideia de uma negação da diferença e a ausência do significante do Nome-do-pai estão entre as explicações etiológicas mais comuns na psicanálise para explicar tanto a homossexualidade como a transexualidade. Cabe ressaltar que o hermafroditismo psíquico também é questionado por Freud (1905/2016a) no primeiro de seus "Três ensaios...", mesmo que o gérmen dessa concepção possa ser pensado ao longo de uma leitura da obra freudiana sobre o desenvolvimento psicossexual da criança. 
No entanto, ainda que a psicanálise afrouxe as certezas no entorno da masculinidade e da feminilidade, calcadas sob signo genital, Freud acaba recorrendo a essa essencialização ao postular que o conjunto de pulsões parciais, a dimensão polimorfa do sexual, recorreria a um objetivo comum, a saber, a organização sob a primazia genital, unindo em um só movimento a eleição de objeto heterossexual e um objetivo final procriador (Ceccarelli, 2013b; Ayouch \& Charafeddine, 2013). Tudo aconteceria como se a heterogeneidade das formações sexuais, em um primeiro momento, fosse afunilada em uma monossexualidade ao final do desenvolvimento psicossexual normal da criança/adolescente. O movimento pendular de Freud faz com que sua proposta ultrapasse e retroceda, a um só tempo, as formulações comuns à ciência psiquiátrica da época.

Nesse sentido, os casos paradigmáticos de Freud, como o caso Hans, o do Presidente Schreber e o Homem dos Lobos, utilizados tanto como ilustração quanto como suporte clínico para a construção do arcabouço metapsicológico, são atravessados por um conjunto de representações sobre o masculino, o feminino, e a sexualidade de maneira geral. Representações essas historicamente localizáveis, implicadas com determinadas concepções acerca do corpo e das relações humanas. Segundo Ayouch (2015),

Todas estas explicações aparecem como restos singulares de uma multiplicidade e são anedóticas no sentido que remetem a situações clínicas individuais e singulares que não cabe generalizar. São etiologias imaginárias que propõem uma teorização fantasmática que vale somente como metaforização pontual, passageira, modificável, na encruzilhada das teorias sexuais-infantis do/a analista e do/a analisando/a. Portanto, nunca devem substituir a clínica e impedir sua escuta. (p. 65)

No que concerne às homossexualidades e transexualidades, o que vemos acontecer ao longo dos anos é a redução da multiplicidade de leituras freudianas sobre o tema em eixos argumentativos estanques, cristalizados, a partir dos quais se estabelece uma leitura prescritiva que baliza o fazer clínico posterior. Assim, a psicanálise caminha no sentido de se constituir como uma doxa normativa, um conglomerado de juízos a partir dos quais os sujeitos serão lidos, classificados e organizados (Ayouch \& Charafedinne, 2013; Arán, 2006). A ressalva é de que esses juízos estão, sim, comprometidos com a manutenção de uma racionalidade heteronormativa cisgênero em Nome-do-pai. Não estaria a psicanálise, desse modo, exercendo uma prática no diapasão do Dispositivo de Sexualidade? Para Foucault (2014) 


\section{ARTIGOS}

É através do isolamento, da intensificação e da consolidação das sexualidades periféricas que as relações do poder com o sexo e o prazer se ramificam e multiplicam, medem o corpo e penetram nas condutas. E, nesse avanço dos poderes, fixam-se sexualidades disseminadas, rotuladas segundo uma idade, um lugar, um gosto, um tipo de prática. Proliferação das sexualidades por extensão do poder; majoração do poder ao qual cada uma dessas sexualidades regionais dá um campo de intervenção (...) Prazer e poder não se anulam; não se voltam um contra o outro; seguem-se, entrelaçam-se e se relançam. (p. 54)

Essa psicanálise, toda ela calcada em um Édipo heterocentrado rígido e em uma estruturação subjetiva pai-orientada, assumiria a ostracização das sexualidades outras e sua exclusão do circuito simbólico (Ayouch, 2015). Insistimos que essa dinâmica não se dá ao acaso e que ela aponta para um atravessamento sócio-histórico no próprio fazer teórico. Além disso, sustentamos que a teorização psicanalítica se assujeitaria aos mecanismos de defesa que ela mesma descobre.

É nesse sentido que Laplanche (1992) vai afirmar que "A teoricogênese reproduz a ontogênese" (p. 17). Aplicando o método de interpretação descoberto por Freud ao próprio texto freudiano, uma atenção equiflutuante a todos os elementos do discurso, mas, nesse caso, a todos os elementos do texto. O leitor do texto deve, então, desempenhar uma função econômica, na qual se dá o mesmo peso para todos esses elementos, seja o todo, partes, detalhes, "qualquer coisa" (Laplanche, 1988, p. 24). Uma espécie de achatamento do texto, sem nada privilegiar, de maneira a desconstruir a organização do discurso e trazer à baila os sentidos latentes que permeiam o texto. Toda aquela superfície que se lê contém invariavelmente elaborações secundárias, defesas e camuflagens do ego; pensar essas elaborações através do método analítico é desmantelar o texto, aplainá-lo, buscar por outras redes de significação.

Argumentamos que desde a patologização da homossexualidade, da qual deriva a transexualidade, essa passa a ser descrita como um distúrbio e até os dias de hoje sofre "[...] as influências desta origem genealógica" (Aran, 2006, p. 52). No curso dessa herança, delineia-se uma repetição tal qual a conhecemos na psicanálise. Em seu texto "Lembrar, repetir e perlaborar" (1914/2016b), Freud vai afirmar que aquelas lembranças que estão sujeitas às maiores resistências não chegarão à consciência como fantasias ou recordações, mas serão atuadas e repetidas. "[...] podemos dizer que o analisando não se lembra de mais nada do que foi esquecido e recalcado, mas ele atua com aquilo. Ele não o reproduz como lembrança, mas como ato, ele repete sem, obviamente, saber o que repete" (p. 154). Aquilo que se repete 
enquanto ato é a leitura patologizante, que se esquece tanto da sexualidade infantil perverso-polimorfa da qual nos fala Freud em seus "Três ensaios..." (1905/2016a) quanto do objeto da pulsão como seu elemento mais variável (Freud, 1915/2017). Cunha (2013) irá nos demonstrar como essa repetição ocorre na história da psicanálise:

É importante notar ainda que não apenas muitos dos argumentos hoje utilizados contra os transexuais, mas até mesmo a sua vinculação a determinados quadros psicopatológicos, como a aproximação com a psicose, já foram utilizados, num passado recente, em referência aos homossexuais. Elizabeth Roudinesco, ao defender, numa entrevista a François Pommier, o direito de os homossexuais serem analistas, lembra que para autores kleinianos da metade do século XX a homossexualidade "foi assimilada a uma patologia dita borderline [...], como variante de um "estado psicótico" [...]. No mesmo diapasão, ela se alinha a seu entrevistador numa crítica dura a Nicos Nicolaidis, psicanalista suíço, por este haver declarado que "a homossexualidade abole a diferença dos sexos e de gerações" [...], curiosamente a mesma acusação que a historiadora e psicanalista, como outros autores, agora lança contra os transexuais [...]. Para Roudinesco, enfim, os homossexuais contemporâneos, com seu desejo de normalização, se aproximam mais da neurose que da perversão e nesse sentido não podem constituir ameaça ao princípio democrático, "fundado sobre a existência da diferença dos sexos e, logo, sobre o casamento heterossexual" [...]. Isto é, dando razão, ao que parece involuntariamente, à crítica dos teóricos queer à psicanálise, Roudinesco acaba por condicionar a regulação democrática do laço social ao reconhecimento da diferença sexual e, mais ainda, à aceitação do binarismo heteronormativo de gênero. Será esse o limite da psicanálise? (Cunha, 2013, pp. 8-9; grifo do autor)

Percebemos que, no cerne dessa repetição, reside o dispositivo da diferença sexual enquanto balizador da estruturação psíquica, um apagamento da diversidade em detrimento da diferença (Laplanche, 1994). Tal lógica de funcionamento comunga com um repertório tradutivo específico, qual seja, o do Édipo e o da castração. Queremos dizer que esses complexos podem ser entendidos como códigos e esquemas narrativos socialmente arranjados, um auxílio à tradução conforme Laplanche. Trata-se de um conjunto organizado de representações de fantasias e afetos cuja origem não é a própria criança. Pelo contrário, fornecidos pelos adultos, eles ajudam a criança a dar forma narrativa às mensagens sexuais que também recebem. "Esses romances, esses roteiros variáveis entre os indivíduos, seriam, pois, da ordem de esquemas narrativos culturalmente transmitidos, e não, como gostaria a teoria clássica, 


\section{ARTIGOS}

da ordem de fantasias filogenéticas, pretensamente 'originárias" (Laplanche, 2015 , p. 286). Não apenas esse esquecimento se produz, retomando a lógica de insuficiência simbólica da psicanálise diante dos fenômenos que escapam à escolha de objeto heterossexual, à identidade cisgênera e à admissão da diferença sexual binária, mas um tropeço diante do qual a teoria retoma seu circuito estereotipado e sinaliza o caminho patologizante para todas essas subjetividades excluídas da norma. A teoria repete, no ato mesmo de produzir um conhecimento sobre as homossexualidades e as transexualidades, por não dispor, em sua conjuntura ortodoxa, de códigos tradutivos para lidar com essas sexualidades. Assim, incorreria em uma dificuldade de lidar com a alteridade que lhe escapa aos fundamentos (Ayouch, 2015).

\section{Conclusão}

A retomada genealógica das sexualidades homo e trans, bem como as explicações etiológicos pela psicanálise, não são isentas de consequências ético-clínico-políticas. Evidenciamos que a psicanálise repetiu com as transexualidades aquilo que outrora foi feito com as homossexualidades, ou seja, utilização de um mesmo padrão de abordagem patologizante. De fato, a psicanálise desde seus primórdios é tributária de um campo de forças mais amplo, o qual poderíamos elencar como próprio ao funcionamento do biopoder (Foucault, 2014). No entanto, não podemos esquecer que a psicanálise ocupa no interior das ciências humanas um lugar diferenciado ao "fazer falar através da consciência o discurso do inconsciente" (Foucault, 1984, p. 391); isso significa que sua capacidade subversiva permanece.

Em suma, entendemos que a solução desse impasse reside no respeito à singularidade clínica, comprometida com a não produção de etiologias para sexualidades que destoam do modelo heterossexual cisgênero, em uma escuta atenta às particularidades de cada sujeito. Desse modo, o psicanalista evitaria transformar o divã em um leito de procusto, em referência ao mito grego, ajustando o paciente ao tamanho da teoria, amputando-lhe os pedaços que excedam ou esticando-os caso sejam pequenos demais. É fundamental que a psicanálise contemporânea revise as medidas desse divã, o qual talvez tenha mutilado tudo aquilo que uma vez ousou transbordá-lo. 


\section{Referências}

Arán, M. (2006). A transsexualidade e a gramática normativa sexo/gênero. Ágora, 9(1), 49-63.

Assis, M. (2019). O alienista. In 25 contos de Machado de Assis (p. 59-101). Belo Horizonte, MG: Autêntica. (Trabalho original publicado em 1882).

Ayouch, T. (2015). Psicanálise \& Homossexualidades: teoria, clínica e biopolítica. Curitiba, PR: Editora CRV.

Ayouch, T., \& Charafeddine L. B. (2013). A homossexualidade dos analistas: história, política e metapsicologia. Percurso, 51, 115-126.

Bedê, M. H., \& Belo, F. R. R. (2019). O analista em cena: uma clínica da transexualidade mais além do diagnóstico. Revista Latinoamericana de Psicopatologia Fundamental, 22(1), 54-71.

Benjamin, H. (1966). The Transsexual Phenomenon. New York, NY: Julian Press.

Butler, J. (1993). Bodies that Matter. On the Discursive Limits of "Sex". New York, NY: Routledge.

Calligaris, C. (1989). Introdução a uma clínica diferencial das psicoses. Porto Alegre, RS: Artes Médicas.

Castel, P. (2001). Algumas reflexões para estabelecer a cronologia do "fenômeno transexual" (1910-1995). Revista Brasileira de História, 41(21), 77-111.

Ceccarelli, P. R. (2013a). Transexualidades. São Paulo, SP: Casa do Psicólogo.

Ceccarelli, P. R. (2013b). O que as homossexualidades têm a dizer à psicanálise (e aos psicanalistas). Bagoas - Estudos gays: gênero e sexualidades, 6(8), 103-123.

Ceccarelli, P. R. (2017). Transexualidades e mudanças discursivas. Estudos de Psicanálise, 47, 151-158.

Ceccarelli, P. R., \& Andrade, E. L. (2018). O sexual, a sexualidade e suas apresentações na atualidade. Revista Latinoamericana de Psicopatologia Fundamental, 21(2), 229-250.

Costa, J. F. (1995). A face e o verso: estudos sobre o homoerotismo II. São Paulo, SP: Escuta.

Cunha, E. L. (2013). Sexualidade e perversão entre o homossexual e o transgênero: Notas sobre psicanálise e teoria Queer. Revista EPOS, 4(2), 12-21.

Dunker, C. I. L. (2015). Mal-estar, sofrimento e sintoma: uma psicopatologia do Brasil entre muros. São Paulo, SP: Boitempo.

Foucault, M. (1984). As ciências humanas. In As palavras e as coisas. (Salma T. Muchail, trad.; pp. 361-404). São Paulo, SP: Martins Fontes.

Foucault, M. (1995). O sujeito e o poder. In H. Dreyfus, P. Rabinow. Michel Foucault: 


\section{ARTIGOS}

uma trajetória filosófica, para além do estruturalismo e da hermenêutica. (Vera P. Carrero, trad.; pp. 231-249). Rio de Janeiro, RJ: Forense Universitária.

Foucault, M. (2001). Os anormais. (Eduardo Brandão, trad.). São Paulo, SP: Martins Fontes.

Foucault, M. (2006). A hermenêutica do sujeito. (Márcio A. da Fonseca e Salma T. Muchail, trads.). São Paulo, SP: Martins Fontes.

Foucault, M. (2014). História da sexualidade I: a vontade de saber. (Maria T. da C. Albuquerque e J. A. G. Albuquerque, trads.). Rio de Janeiro, RJ: Graal.

Foucault, M. (2017). Microfísica do poder. (Roberto Machado, trad.). São Paulo, SP: Paz \& Terra.

França, C. P., \& Mazzini, C. A. (2018). Encontros e desencontros entre Laplanche e Lacan: abordagens psicanalíticas das questões sociais. Psicologia Clínica, 30(2), 211-228.

Freud, S. (2011). Sobre a psicogênese de um caso de homossexualidade feminina. In Obras completas (Vol. 15; pp. 114-149). São Paulo, SP: Companhia das Letras. (Trabalho original publicado em 1920).

Freud, S. (2015). Uma lembrança de infância de Leonardo da Vinci. In Obras Incompletas de Sigmund Freud: Arte, literatura e os artistas (pp. 69-166). Belo Horizonte, MG: Autêntica. (Trabalho original publicado em 1910).

Freud, S. (2016a). Três ensaios sobre a teoria da sexualidade. In Obras completas (Vol. 6; pp. 20-154). São Paulo, SP: Companhia das Letras. (Trabalho original publicado em 1905).

Freud, S. (2016b). Recordar, repetir e perlaborar. In Obras Incompletas de Sigmund Freud: Fundamentos da Clínica Psicanalítica. (pp. 151-164). Belo Horizonte, MG: Autêntica. (Trabalho original publicado em 1914).

Freud, S. (2017). As pulsões e seus destinos. In Obras Incompletas de Sigmund Freud: As pulsões e seus destinos. (pp. 13-72). Belo Horizonte, MG: Autêntica. (Trabalho original publicado em 1915).

Katz, J. N. (1996). A invenção da heterossexualidade. (Clara Fernandes, trad.). Rio de Janeiro, RJ: Ediouro.

Lacan, J. (1988). O seminário. Livro 3. As psicoses. (Aluísio Menezes, trad.). Rio de Janeiro, RJ: Jorge Zahar. (Trabalho original publicado em 1955-56).

Lacan, J. (1996). Entretien avec Michel H. In Sur l'identité sexuelle: à propos $d u$ transsexualisme (Obra coletiva). Paris, France: Association Freudienne Internationale.

Lacan, J. (1998). Escritos. (Vera Ribeiro, trad.). Rio de Janeiro, RJ: Jorge Zahar. (Trabalho original publicado em 1966).

Lacan, J. (2005). O seminário. Livro 10. A angústia. Rio de Janeiro, RJ: Jorge Zahar. (Trabalho original publicado em 1962-63). 
Laplanche, J. (1988). Interpretar (com) Freud. In Teoria da sedução generalizada e outros ensaios (pp. 21-32). Porto Alegre, RS: Artes Médicas.

Laplanche, J. (1992). A revolução copernicana inacabada. Percurso, 56/57, 15-34.

Laplanche, J. (1994). O sexual, suas mensagens e traduções. Percurso, 13(2), 83-93.

Laplanche, J. (2015). Castração e Édipo como códigos e esquemas narrativos. In Sexual: a sexualidade ampliada no sentido freudiano 2000-2006 (pp. 280-287). Porto Alegre, RS: Dublinense.

Lattanzio, F., \& Ribeiro, P. C. (2017). Transexualidade, psicose e feminilidade originária: entre psicanálise e teoria feminista. Psicologia USP. 1(28), 72-82.

Lattanzio, F., \& Ribeiro, P. de C. (2018). Nascimento e primeiros desenvolvimentos do conceito de gênero. Psicologia Clínica, 30(3), 409-425.

Millot, C. (1991). Extrasexo: ensaios sobre o transexualismo. São Paulo, SP: Escuta.

Miranda, E. R. (2015). Transexualidade e Sexuação. Stylus Revista de Psicanálise do Rio de Janeiro, 30, 91-99.

Perelson, S. (2011). Transexualismo: uma questão do nosso tempo e para nosso tempo. ÉPOS, 2(2), 1-19.

Porchat, P. (2014). Psicanálise e transexualismo: desconstruindo gêneros e patologias com Judith Butler. Curitiba, PR: Juruá.

Stoller, R. (1966). The mother's contribution to infantile transvestic behavior. International Journal of Psychoanalysis, 47, 384-395.

Trillat, E. (1991). A história da histeria. São Paulo, SP: Escuta.

Yoshida, L. A. M., Pereira, C.B.D., Sousa, L. M., Klein, S. M. R. P., \& Cordeiro, S. N. (2001). Transexualismo: uma visão psicanalítica. Revista Latinoamericana de Psicopatologia Fundamental, IV(2), 92-112.

Agradecimentos: Agradecemos ao prof. dr. Thamy Ayouch pela gentileza de compartilhar parte de suas pesquisas e pelas indicações bibliográficas.

\section{Resumos}

(Theorizing, repeating and pathologizing: the psychoanalytical understanding of homosexualities and transsexualities)

This work aims to localize the intertwining of common or repeated elements in psychoanalytic theorizations about homosexuality and transsexuality. By characterizing psychoanalytic discourses from Freud and Lacan to our days, we find a kind of repetition in these theorizations, since homosexuality has historically been associated 


\section{ARTIGOS}

to a choice of narcissistic object and perversion, a fact that is repeated nowadays in postulations about transsexualities, which are described as psychosis and perversion. We conclude that a large number of psychoanalytic texts are linked, intertwined and informed by repeating theories such as the thesis of psychic hermaphroditism that serves as the etiological basis for both homosexualities and transsexualities.

Key words: Homosexuality, psychoanalysis, repeating, transsexuality

(Théoriser, répéter et pathologiser: la lecture psychanalytique sur les homosexualités et les transsexualités)

L'objectif de ce travail est de localiser le métissage des éléments communs ou répétés dans les théories psychanalytiques autour de l'homosexualité et de la transsexualité. La caractérisation des discours psychanalytiques depuis Freud et Lacan jusqu'à aujourd'hui consiste en une sorte de répétition dans ces théories, étant donné que l'homosexualité a toujours été liée au choix de l'objet narcissique et à la perversion, fait qui se reproduit aujourd'hui dans des postulats sur les transsexualités, prises comme psychose et perversion. Nous concluons que de nombreux textes psychanalytiques sont liés, entrelacés et complétés par une répétition de théories telles que la thèse de l'hermaphrodisme psychique qui sert de base étiologique à la fois à l'homosexualité et à la transsexualité.

Mots clés: Homosexualité, psychanalyse, répétition, transsexualité

(Teorizar, repetir y patologizar: la lectura psicoanalítica acerca de las homosexualidades y transexualidades)

El objetivo de este trabajo es localizar el entrecruzamiento de los elementos comunes o que se repiten en las teorizaciones psicoanalíticas sobre la homosexualidad y la transexualidad. Desde la caracterización de los discursos psicoanaliticos desde Freud y Lacan hasta nuestros dias, hemos constatado una especie de repetición en estas teorizaciones, ya que la homosexualidad ha estado históricamente vinculada a una elección narcisista de objeto y a la perversión, un hecho que se repite en la actualidad en las postulaciones sobre las Transexualidades, vistas como psicosis y perversión. Se concluye que muchos textos psicoanaliticos se articulan, entrelazan y complementan en una repetición de teorías como la tesis del hermafroditismo psíquico que sirve como base etiológica tanto para la homosexualidad como para la transexualidad.

Palabras claves: Homosexualidad, psicoanálisis, repetición, transexualidad

Citação/Citation: Almeida, P. T. de, Castro, M. F. de, \& Ribeiro, S. D. (2020, março). Teorizar, repetir e patologizar: a leitura psicanalítica sobre as homossexualidades e transexualidades. Revista Latinoamericana de Psicopatologia Fundamental, 23(1), 77-98. http:// dx.doi.org/10.1590/1415-4714.2020v23n1p77.6. 
Editora/Editor: Profa. Dra. Ana Maria G. R. Oda

Submetido/Submitted: 30.08 .2019 / 08.30.2019 Revisado/Revised: $21.01 .2020 / 01.21 .2020$

Aceito/Accepted: $21.01 .2020 / 01.21 .2020$

Copyright: (C) 2009 Associação Universitária de Pesquisa em Psicopatologia Fundamental/ University Association for Research in Fundamental Psychopathology. Este é um artigo de livre acesso, que permite uso irrestrito, distribuição e reprodução em qualquer meio, desde que o autor e a fonte sejam citados / This is an open-access article, which permits unrestricted use, distribution, and reproduction in any medium, provided the original authors and sources are credited.

Financiamento/Funding: Este trabalho não recebeu apoio / This work received no funding.

Conflito de interesses/Conflict of interest: Os autores declaram que não há conflito de interesses. / The authors declare that there is no conflict of interest.

\section{Pedro Teixeira de Almeida}

Mestrando em Estudos Psicanalíticos pela Universidade Federal de Minas Gerais - UFMG (Belo Horizonte, MG, Br); Membro voluntário do grupo de pesquisa Psicanálise e Política. Av. Fleming, 294/301, B1. 3 - Ouro Preto

98 31310-490 Belo Horizonte, MG, Br

Teixeiraemp@gmail.com

https://orcid.org.0000-0001-5779-6626

\section{Matheus Ferreira de Castro}

Graduando em Psicologia pela Universidade Federal de Minas Gerais - UFMG (Belo Horizonte, MG, Br); Membro do Projeto CAVAS/UFMG e estagiário em psicologia no Hospital HRTN (Belo Horizonte, MG, Br).

Rua Boaventura, 1319/104, B1. 8 - Liberdade

31270-310 Belo Horizonte, MG, Br

mathfcastro@gmail.com

https://orcid.org.0000-0002-7106-8892

\section{SARUg DAgir Ribeiro}

Doutoranda em Psicologia pela Universidade Federal de Minas Gerais - UFMG (Belo Horizonte, MG, Br); Mestre em Letras; Psicóloga Clínica. (Belo Horizonte, MG, Br).

Rua 36, n. 320/104, B1.2 - Gávea

33200-000 Vespasiano, MG, Br

sdagir@gmail.com

https://orcid.org.0000-0001-8251-6710

This is an open-access article, which permits unrestricted use, distribution, and reproduction in any medium for non-commercial purposes provided the original authors and sources are credited. 